\title{
The Identity of a Single Residue of the RNA-Dependent RNA Polymerase of Grapevine Fanleaf Virus Modulates Vein Clearing in Nicotiana benthamiana
}

\author{
Larissa J. Osterbaan, ${ }^{1, \dagger}$ Jiyeong Choi, ${ }^{1}$ Jaimie Kenney, ${ }^{1}$ Madison Flasco, ${ }^{1}$ Emmanuelle Vigne, ${ }^{2}$ \\ Corinne Schmitt-Keichinger, ${ }^{2}$ Ana Rita Rebelo, ${ }^{3}$ Michelle Heck, ${ }^{3,4,5}$ and Marc Fuchs ${ }^{1}$ \\ ${ }^{1}$ Cornell University, Plant Pathology and Plant-Microbe Biology Section, School of Integrative Plant Science, Cornell AgriTech \\ at the New York State Agricultural Experiment Station, Geneva, NY 14456, U.S.A. \\ ${ }^{2}$ UMR 1131 Santé de la Vigne et Qualité du Vin, INRA-Université de Strasbourg, 68000 Colmar, France \\ ${ }^{3}$ Emerging Pests and Pathogens Research Unit, USDA Agricultural Research Service, Robert W. Holley Center for Agriculture \\ and Health, Ithaca, NY, U.S.A. \\ ${ }^{4}$ Boyce Thompson Research Institute for Plant Research, 533 Tower Road, Ithaca, NY 14853, U.S.A. \\ ${ }^{5}$ Cornell University, Plant Pathology and Plant-Microbe Biology Section, School of Integrative Plant Science, Cornell University, \\ Ithaca, NY, 14853, U.S.A.
}

Accepted 7 January 2019.

The mechanisms underlying host plant symptom development upon infection by viruses of the genus Nepovirus in the family Secoviridae, including grapevine fanleaf virus (GFLV), are poorly understood. In the systemic host Nicotiana benthamiana, GFLV strain GHu produces characteristic symptoms of vein clearing in apical leaves, unlike other GFLV strains such as F13, which cause an asymptomatic infection. In this study, we expanded on earlier findings and used reverse genetics to identify residue 802 (lysine, $K$ ) of the GFLV-GHu RNA1-encoded RNA-dependent RNA polymerase $\left(1 \mathrm{E}^{\mathrm{Pol}}\right)$ as a modulator of vein-clearing symptom development in $N$. benthamiana. Mutations to this site abolished (K to G, A, or $\mathbf{Q}$ ) or attenuated ( $\mathrm{K}$ to $\mathbf{N}$ or $\mathrm{P}$ ) symptom expression. Noteworthy, residue 802 is necessary but not sufficient for vein clearing, as GFLV-F13 RNA1 carrying $K^{802}$ remained asymptomatic in $N$. benthamiana. No correlation was found between symptom expression and RNA1 accumulation, as shown by reverse transcription-quantitative polymerase chain reaction. Additionally, the involvement of RNA silencing of vein clearing was ruled out by virus-induced gene silencing experiments and structure predictions for protein $1 E^{\mathrm{Pol}}$ suggested that residue 802 is flanked by strongly predicted stable secondary structures, including a conserved motif of unknown function ${ }^{805}$ LLKT/AHLK/RT/ALR $\left.{ }^{814}\right)$. Together, these results reveal the

Current address for Jaimie Kenney: University of California, Riverside, Department of Entomology, College of Natural and Agricultural Sciences, Riverside, CA 92521, U.S.A.

${ }^{\dagger}$ Corresponding author: L. Osterbaan; 1jo29@cornell.edu

Funding: This work was funded by Director of Cornell AgriTech Endowed funds, Federal Capacity Funds, College of Agriculture and Life Sciences, Cornell University Schmittau-Novak Integrative Plant Science grant, and National Institute of Food and Agriculture grant 2018-67011-28107.

*The $\boldsymbol{e}$-Xtra logo stands for "electronic extra" and indicates that two supplementary figures and six supplementary tables are published online.

The author(s) declare no conflict of interest.

๑) 2019 The American Phytopathological Society protein nature of the GFLV-GHu symptom determinant in $N$. benthamiana and provide a solid basis for probing and determining the virus-host proteome network for symptoms of vein clearing.

Grapevine fanleaf virus (GFLV) is one of several viruses from the genus Nepovirus in the family Secoviridae, which is responsible for fanleaf degeneration of grapevines. This disease is one of the most costly viral diseases of grapevine worldwide, causing massive yield losses due to uneven and poor berry set and decreased vine productive lifespan (Digiaro et al. 2017; Schmitt-Keichinger et al. 2017). The symptoms of GFLV in grapevine include vein yellowing, mosaics, internode shortening, and the virus' namesake 'fanleaf' symptom characterized by abnormally open petiolar sinuses and diminished lobing (Schmitt-Keichinger et al. 2017). The molecular mechanisms underlying these symptoms remain unknown.

Like all nepoviruses, GFLV has a bipartite positive-sense RNA genome. Each RNA contains a single open reading frame that is expressed by monocistronic translation followed by proteolytic processing by the viral protease $1 \mathrm{D}^{\text {Pro }}$ (Fuchs et al. 2017; Schmitt-Keichinger et al. 2017). RNA1 contains the viral proteins necessary for genome replication and polyprotein processing. Therefore, RNA1 is capable of replication independent of RNA2; however, plant systemic infection can only occur if both genomic RNAs are present (Viry et al. 1993). The other proteins of RNA1 include 1A, of unknown function; $1 \mathrm{~B}^{\mathrm{Hel}}$, a putative helicase (HEL); $1 \mathrm{C}^{\mathrm{VPg}}$, a genome-linked viral protein; and $1 \mathrm{E}^{\mathrm{Pol}}$, a canonical RNA-dependent RNA polymerase (RdRp) (Schmitt-Keichinger et al. 2017). The proteins encoded by RNA 2 include $2 \mathrm{~A}^{\mathrm{HP}}$, a putative homing protein; $2 \mathrm{~B}^{\mathrm{MP}}$, a tubule-type movement protein; and $2 \mathrm{C}^{\mathrm{CP}}$, the coat protein that makes up the pseudo $\mathrm{T}=3$ icosahedron of the GFLV capsid and is responsible for virus-vector specificity (SchmittKeichinger et al. 2017). To date, no GFLV protein has shown definitive silencing-suppressor activity, although the coat protein of tomato ringspot virus (ToRSV), another nepovirus, was documented as a weak silencing suppressor (Karran and Sanfaçon 2014). 
How plant viruses produce symptoms in their hosts is a long-standing question in plant pathology. An early hypothesis was the competitive disease model, which proposed that plant viruses replicate so prodigiously in their hosts as to outcompete host components for access to cellular resources, essentially starving the host at the cellular level (Culver and Padmanabhan 2007). While some plant viruses are able to accumulate to remarkably high levels in their hosts, the fact that the presence and severity of symptoms often cannot be strictly correlated to virus titer (Duff-Farrier et al. 2015; Fujita et al. 2018; Mansilla et al. 2009; RodríguezCerezo et al. 1991) suggests that the competitive disease model is not sufficient to explain the mechanism by which virus infection leads to symptoms.

A more recent and compelling explanation for viral symptom development in planta is the interaction disease model, which proposes that alterations of host physiology are the result of specific interactions between viral and host components (Culver and Padmanabhan 2007). Indeed, several cases of interactions between viral proteins with specific host components have been reported in the literature and such interactions have been conclusively linked to symptom development (García and Pallás 2015).

The identity and function of viral symptom determinants (also commonly called pathogenicity determinants) are quite varied and include RdRps (Mansilla et al. 2009; Liu et al. 2017; Padmanabhan et al. 2005; Vigne et al. 2013), movement proteins (Hasiów-Jaroszewska et al. 2011; Rao and Grantham 1995), helper component-proteases (Shiboleth et al. 2007), capsid proteins (Hasiów-Jaroszewska et al. 2013; Heaton et al. 1991; Qiu et al. 2018) and a cysteine-rich protein (Fujita et al. 2018). In addition to their basic functions, many viral protein symptom determinants possess RNA silencing suppression activity (Fujita et al. 2018; Shiboleth et al. 2007). Some studies have even mapped symptom determinants to individual amino acids (aa) (Heaton et al. 1991; Kagiwada et al. 2005; Ozeki et al. 2006), and, in one instance, the symptom determinant (modulator) and symptom elicitor are separate viral components (Komatsu et al. 2011). However, there have also been instances in which symptom determinants are based on nucleotide (nt) sequences, such as satellite RNAs (Shimura et al. 2011; Smith et al. 2011), or noncoding regions of the genome, such as $5^{\prime}$ and $3^{\prime}$ untranslated regions (Rodríguez-Cerezo et al. 1991).

GFLV isolates may be mechanically transmitted from grapevine tissue to herbaceous plants, including Nicotiana benthamiana, a model host plant that sustains systemic virus infection. Most strains of GFLV, including strain F13, are asymptomatic in $N$. benthamiana; however, strain GFLV-GHu elicits distinctive symptoms of vein clearing on the upper, uninoculated leaves of $N$. benthamiana (Vigne et al. 2013). These observations suggested that GFLV-GHu encodes a strain-specific symptom determinant. A previous investigation mapped the $\mathrm{GHu}$ symptom determinant to the 408 nt (136 aa) at the $3^{\prime}$ end of the coding region of $1 \mathrm{E}^{\mathrm{Pol}}$. However, it was not determined if the underlying mechanism is dependent on the nt or aa sequence (Vigne et al. 2013). We recently developed a series of binary plasmids carrying the full-length cDNAs of RNA1 and RNA2 of GFLV strains F13 and GHu for the rapid generation of mutant GFLV RNA1 constructs (Osterbaan et al. 2018). We used this system to characterize the nature of the GFLV-GHu symptom determinant and examine whether it acts at the nt or aa level. Here, we report vein clearing symptom development for GFLV-GHu in $N$. benthamiana is dependent on the identity of residue 802 of protein $1 \mathrm{E}^{\mathrm{Pol}}$.

\section{RESULTS}

The symptom determinant lies within the ultimate $162 \mathrm{nt}$ ( 54 residues) of the GFLV-GHu $1 E^{\text {Pol }}$ coding region.

Vigne et al. (2013) had previously narrowed down the symptom determinant to the $3^{\prime}$ ultimate $408 \mathrm{nt}$ (136 aa) of the GFLV-GHu $1 \mathrm{E}^{\mathrm{Pol}}$ coding region (Fig. 1A). We hypothesized that the minimal GFLV-GHu symptom determinant is a subset of these $408 \mathrm{nt}$ [136 aa] and sought to identify the minimal region of the GFLV-GHu $1 \mathrm{E}^{\mathrm{Pol}}$ coding region responsible for symptom development by creating series of chimeras swapping short nt sequences between GFLV strains GHu and F13 to characterize the nature of GFLV-GHu vein clearing determinant.

Nine GFLV RNA1 chimeric constructs were obtained and were used with a GFLV-GHu RNA2 construct in Agrobacterium tumefaciens-mediated inoculation (agroinoculation) of $N$. benthamiana. In replicated experiments of at least five plants each, three constructs (GHu 2065-2130 ${ }_{\mathrm{F} 13}, \mathrm{GHu} 2131$ $2220_{\mathrm{F} 13}$, and $\mathrm{GHu} 2221-2310_{\mathrm{F} 13}$ ) were able to establish systemic infection in $N$. benthamiana, as shown by double-antibody sandwich enzyme-linked immunosorbent assay (DAS-ELISA), and produced symptoms of vein clearing typical of wild-type GHu (Figs. 1C and 2M to O) while six constructs (four F13based constructs, plus $\mathrm{GHu} 2311-2400_{\mathrm{F} 13}$, and $\mathrm{GHu} 2401$ $2472_{\mathrm{F} 13}$ ) failed to establish systemic infection (Fig. 1C). Sequencing of the $3^{\prime}$ end of the $1 \mathrm{E}^{\text {Pol }}$ coding region of virus progeny showed that the three systemically infectious constructs retained the engineered chimeric regions, with no indels or substitutions detected within the $3^{\prime}$ ultimate $500 \mathrm{nt}$ of the $1 \mathrm{E}^{\mathrm{Pol}}$ coding region. The chimeric regions of the three infectious and symptomatic constructs together span nt 2,065 to 2,310 (aa 689 to 770 ) of the $1 \mathrm{E}^{\mathrm{Pol}}$ coding region (Fig. 1C). Since alteration of this region had no effect on the ability of GFLV-GHu to produce vein clearing in $N$. benthamiana, we concluded that it is not directly involved in symptom development. Since chimeras targeting the remaining sequence (nts 2,311 to 2,472 [aa 771 to 824 ]) did not cause systemic infection in $N$. benthamiana, we were not able to determine what role the remaining $162 \mathrm{nt}$ (54 aa) play in vein clearing.

\section{Unique aa within the 54 ultimate residues of GFLV-GHu $1 \mathrm{E}^{\mathrm{Pol}}$ are not necessary for vein-clearing symptoms.}

We hypothesized that the symptom determinant may be a component unique to the GHu strain because it is the only GFLV strain known to cause symptoms of vein clearing in $N$. benthamiana (E. Vigne and M. Fuchs personal observation). Therefore, unique GFLV-GHu $1 \mathrm{E}^{\mathrm{Pol}}$ aa were identified within the ultimate 54 residues following sequence alignments, and point mutants were created to further pinpoint the symptom determinant. A search of GenBank as of December 2017 uncovered a total of 22 GFLV entries containing sequences of the ultimate $162 \mathrm{nt}$ ( 54 residues) of $1 \mathrm{E}^{\mathrm{Pol}}$. By aligning the 22 sequences, 5 aa unique to the GHu strain were identified within this region, namely, $\mathrm{V}^{779}, \mathrm{~V}^{791}, \mathrm{H}^{800}, \mathrm{~A}^{818}$, and $\mathrm{P}^{822}$ (Fig. 3A).

In a gain-of-function assay, we made a set of point mutations targeting residues 779, 791, and 800 for which the GFLV-F13 aa was mutated to the GHu residue using a GFLV-F13 RNA1 in-vitro RNA transcription construct. Following mechanical inoculation of in-vitro transcripts, each of these mutants was systemically infectious in the presence of functional GFLV-F13 RNA2, as shown by DAS-ELISA, but was asymptomatic in $N$. benthamiana. Sequencing of RNA1 of viral progeny confirmed retention of the engineered mutations. In a parallel loss-of-function assay, we made point mutations 
targeting residues $779,791,800,818$, and 822 in a GFLV-GHu RNA1 binary plasmid. We also produced constructs bearing silent mutations at each of these sites to determine if changes to symptom expression, if any, were dependent on changes to the aa or nt sequence. All mutants were used in A. tumefaciens-mediated inoculation of $N$. benthamiana in the presence of GFLV-GHu RNA2. All ten of the constructs were systemically infectious in $N$. benthamiana, as shown by DAS-ELISA, and produced typical GFLV-GHu vein clearing (Fig. 2R to V). Additionally, simultaneous mutation of $\mathrm{H}^{800}$ and $\mathrm{P}^{822}$ had no effect on symptom development (Fig. $2 \mathrm{~W}$ and $\mathrm{X}$ ). As before, sequencing of viral progeny confirmed retention of the engineered mutations. These findings revealed that aa $\mathrm{V}^{779}, \mathrm{~V}^{791}, \mathrm{H}^{800} \mathrm{~A}^{818}$, and $\mathrm{P}^{822}$, which had

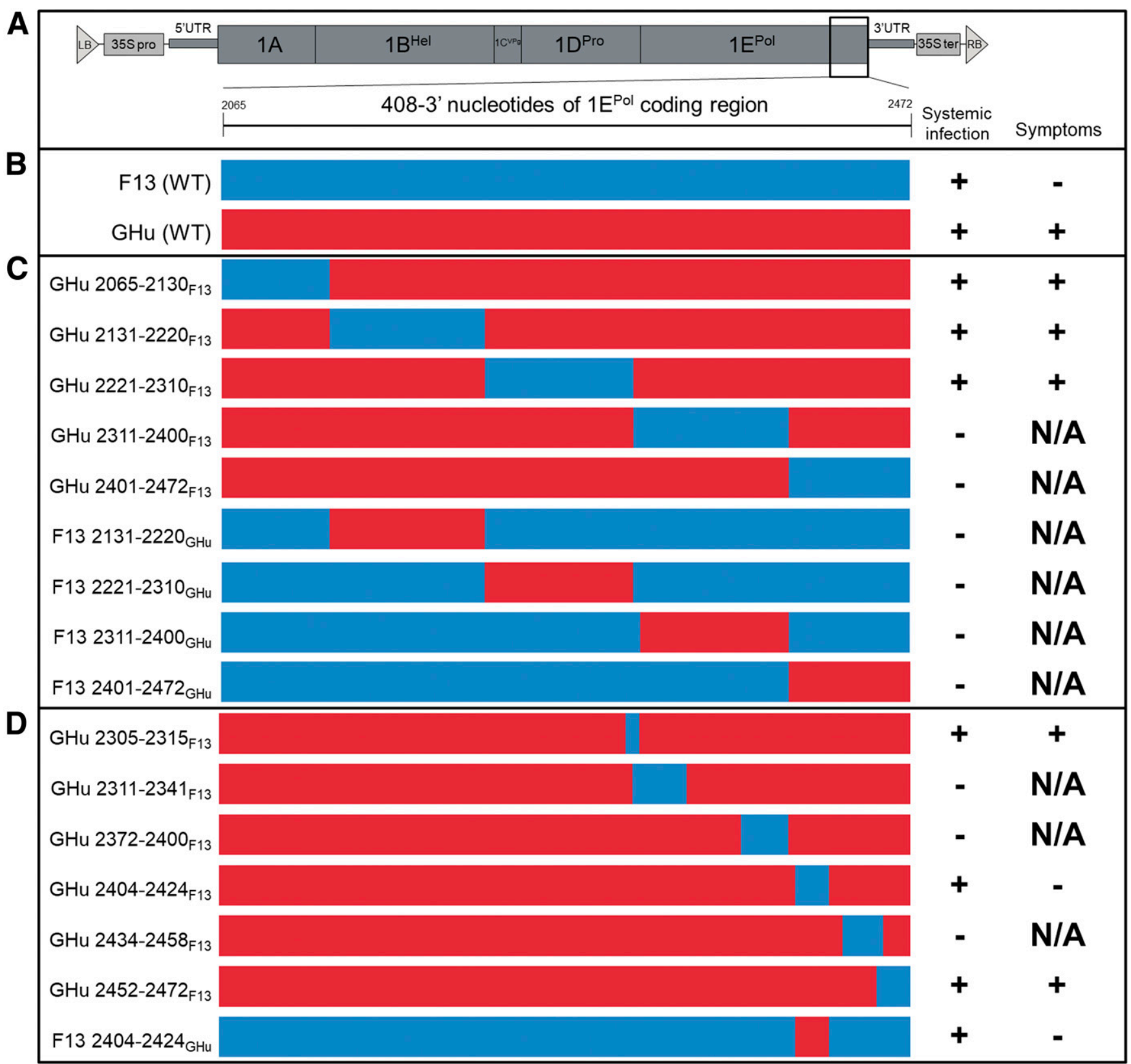

Fig. 1. Grapevine fanleaf virus (GFLV) $1 \mathrm{E}^{\mathrm{Pol}}$ chimeras and their behavior in Nicotiana benthamiana following agroinoculation. A, Schematic of GFLV RNA1 cDNA within the T-DNA region of pCLEAN-G181, a binary vector. The box at the $3^{\prime}$ end of the $1 \mathrm{E}^{\mathrm{Pol}}$ coding region indicates the 408 nucleotide stretch that was targeted for mutagenesis in the creation of the chimeras and is equivalent to the full-length boxes in the other parts of the figure. B, Both RNA1 of GFLV strains F13 and GHu are systemically infectious in $N$. benthamiana via agroinoculation in the presence of GFLV-GHu RNA2, with F13 causing an asymptomatic infection and GHu causing symptoms of vein clearing on systemically infected leaves. Blue boxes indicate sequences of GFLV-F13 origin; red boxes represent sequences of GFLV-GHu origin. C, Chimeras in which regions of 66 to $90 \mathrm{nt}$ of the 408 -nt symptom determinant region were exchanged between strains GHu and F13. D, Chimeras in which regions of 11 to 31 nt lying in the $3^{\prime}$ ultimate 162 nt of the $1 \mathrm{E}^{\text {Pol }}$ coding region were exchanged between strains GHu and F13. In B to D, the first column shows the construct name, with the first word designating the strain origin of the RNA1 (F13 or GHu) and the numbers indicating which stretch of nucleotides of the $1 \mathrm{E}^{\mathrm{Pol}}$ coding region were mutated to the cognate sequence of the other strain, with the subscript indicating the source of the chimeric region. The second column is a cartoon representation of the chimeric region of the construct. The third column indicates whether the construct was able to establish systemic infection in $N$. benthamiana via agroinoculation, as determined by double-antibody sandwich enzymelinked immunosorbent assay using specific GFLV antibodies. The fourth column indicates if the construct produced typical symptoms of GFLV-GHu vein clearing. 
been identified as unique to GFLV-GHu within the 54 ultimate residues of protein $1 \mathrm{E}^{\mathrm{Pol}}$, are not necessary for symptoms of vein clearing in $N$. benthamiana (Supplementary Table S1).

\section{GFLV-GHu symptoms of vein clearing are abolished} by mutation of nt 2,404 to 2,424 (residues 801 to 808 ) of the $1 \mathrm{E}^{\mathrm{Pol}}$ coding region.

Given that RNA1 chimeras targeting large regions of the $1 \mathrm{E}^{\mathrm{Pol}}$ protein often did not cause systemic infection (Fig. 1C), we further investigated the symptom determinant region by creating chimeras targeting smaller regions. We produced six such chimeras based on GHu RNA1. In replicated experiments of at least five plants each, three constructs $(\mathrm{GHu}$
$2311-2341_{\mathrm{F} 13}$, GHu 2372-2400 ${ }_{\mathrm{F} 13}$, and $\mathrm{GHu} 2434-2458_{\mathrm{F} 13}$ ) failed to establish systemic infection in $N$. benthamiana via agroinoculation, once again highlighting the sensitivity of this region of $1 \mathrm{E}^{\mathrm{Pol}}$ to modifications that abolish the ability of the virus to systemically infect plants. Of the three systemically infectious constructs, one failed to produce typical $\mathrm{GHu}$ symptoms (GHu 2404-2424 $4_{\mathrm{F} 13}$ ) (Table 1; Fig. 2E). This was our first incidence of a construct with a GHu RNA1 backbone that was unable to produce vein clearing. To determine if the cognate chimera could produce symptoms with a F13 RNA1 background, we produced F13 2404$2424_{\mathrm{GHu}}$. Though this construct was systemically infectious, as shown by DAS-ELISA, it remained asymptomatic in
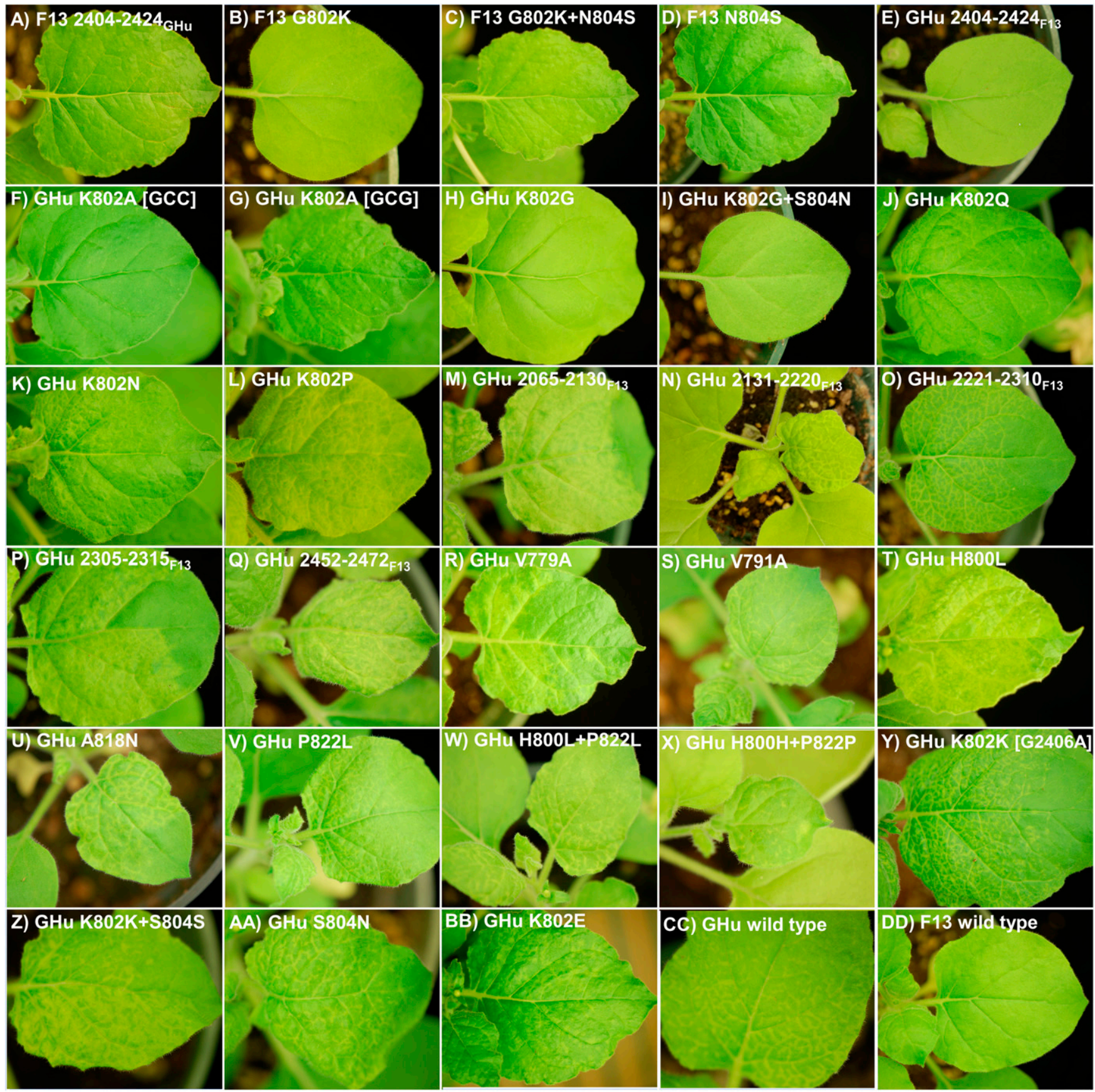

Fig. 2. Symptoms of vein clearing or absence thereof on Nicotiana benthamiana plants systemically infected with select grapevine fanleaf virus (GFLV) RNA1 constructs and GFLV-GHu RNA2 following agroinoculations. A to J, Asymptomatic chimeric and mutant GFLV RNA1 constructs. K to L, GFLV RNA1 constructs generating weak symptoms. M to AA, Symptomatic chimeric and mutant GFLV RNA1 constructs. BB, Single instance of a symptom of vein clearing produced by GHu K802E. CC, Wild-type GFLV-GHu. DD, Wild-type GFLV-F13. Apical, systemically infected leaves were photographed 8 to 14 days postinoculation. 
N. benthamiana (Table 1; Fig. 2A). Sequencing of reverse transcription-polymerase chain reaction (RT-PCR) products showed that RNA1 of virus progeny of systemically infectious constructs maintained the targeted mutations. This work revealed that GFLV-GHu vein clearing can be abolished by mutating nt 2,404 to 2,424 (residues 801 to 808 ) of the $1 \mathrm{E}^{\mathrm{Pol}}$ coding region. This region was further dissected to determine the nature of the vein clearing determinant.

GFLV-GHu vein clearing is dependent on the identity of residue 802 of the $1 \mathrm{E}^{\mathrm{Pol}}$ protein.

We hypothesized that a single aa within residues 801 to 808 of the $1 \mathrm{E}^{\mathrm{Pol}}$ protein is causing vein clearing in $N$. benthamiana. Of these 7 aa, only two are not conserved between GFLV strains $\mathrm{GHu}$ and $\mathrm{F} 13$, i.e., $\mathrm{K}^{802} / \mathrm{G}^{802}$ and $\mathrm{S}^{804} / \mathrm{N}^{804}(\mathrm{GHu} / \mathrm{F} 13$, respectively). We created single and double residue mutants (as well as silent mutations) targeting these sites in RNA1 of both GFLV-GHu and GFLV-F13 (Table 1) and inoculated them to $N$. benthamiana via A. tumefaciens in the presence of GFLVGHu RNA2. Notably, mutation of GFLV-GHu $1 \mathrm{E}^{\mathrm{Pol}}$ lysine 802 to glycine (construct $\mathrm{GHu} \mathrm{K} 802 \mathrm{G}$ ) abolished symptoms, while silent mutation at this site (GHu K802K [G2406A]) had no effect on systemic infection and development of vein clearing (Table 1; Fig. $2 \mathrm{H}$ and $\mathrm{Y}$ ). Also, mutation of GFLV-GHu $1 \mathrm{E}^{\mathrm{Pol}}$ serine 804 to asparagine $(\mathrm{GHu} \mathrm{S} 804 \mathrm{~N})$ as well as silent mutation at this site (GHu S804S [AGC to TCT]), had no effect on systemic infection and development of vein clearing (Table 1; Fig. 2AA).
Furthermore, reciprocal mutations to GFLV-F13 RNA1 (F13 G802K, F13 G802G [C2406G], F13 N804S, and F13 N804N [T2412C]) all produced asymptomatic systemic infections typical of wild-type GFLV-F13 (Table 1; Fig. 2B and D). Sequencing of RT-PCR products from RNA1 of virus progeny of single and dual mutants showed that the targeted mutations were maintained. These data confirmed our hypothesis by indicating that GFLV-GHu vein clearing is dependent on the identity of residue 802 of the $1 \mathrm{E}^{\mathrm{Pol}}$ protein.

\section{The nature of residue 802 of the $1 \mathrm{E}^{\mathrm{Pol}}$ protein of GFLV- GHu modulates symptom expression in $N$. benthamiana.}

To investigate whether the nature of aa 802 of GFLV-GHu $1 \mathrm{E}^{\mathrm{Pol}}$ modulates development of vein clearing in $N$. benthamiana, we mutated this residue to several other aa covering a range of chemistries and structures. Mutation of GFLV-GHu $1 \mathrm{E}^{\mathrm{Pol}}$ lysine 802 to alanine (GHu K802A [GCC] and GHu K802A [GCG]) or glutamine (GHu K802Q) abolished symptoms of vein clearing in $N$. benthamiana (Table 1; Fig. $2 \mathrm{~F}, \mathrm{G}$, and $\mathrm{J}$ ). Mutation of this residue to glutamic acid, asparagine, or proline (GHu K802E, $\mathrm{N}$, and $\mathrm{P}$, respectively) produced symptoms that did not perfectly mimic those of wild-type GFLV-GHu. Mutant GHu K802E generally produced asymptomatic infections; however, in one inoculation experiment, one of four plants that became systemically infected, as shown by DAS-ELISA, displayed distinct symptoms of vein clearing (Fig. 2BB). Sequencing of the $3^{\prime}$ end of the $1 \mathrm{E}^{\mathrm{Pol}}$
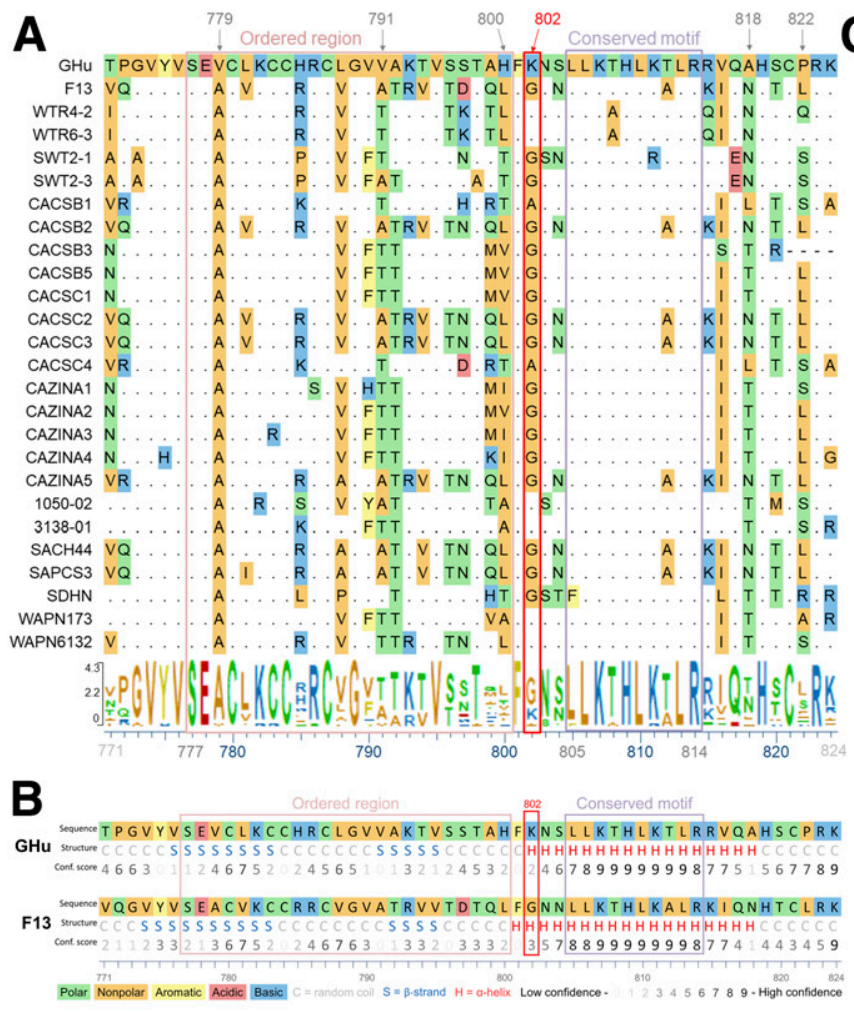

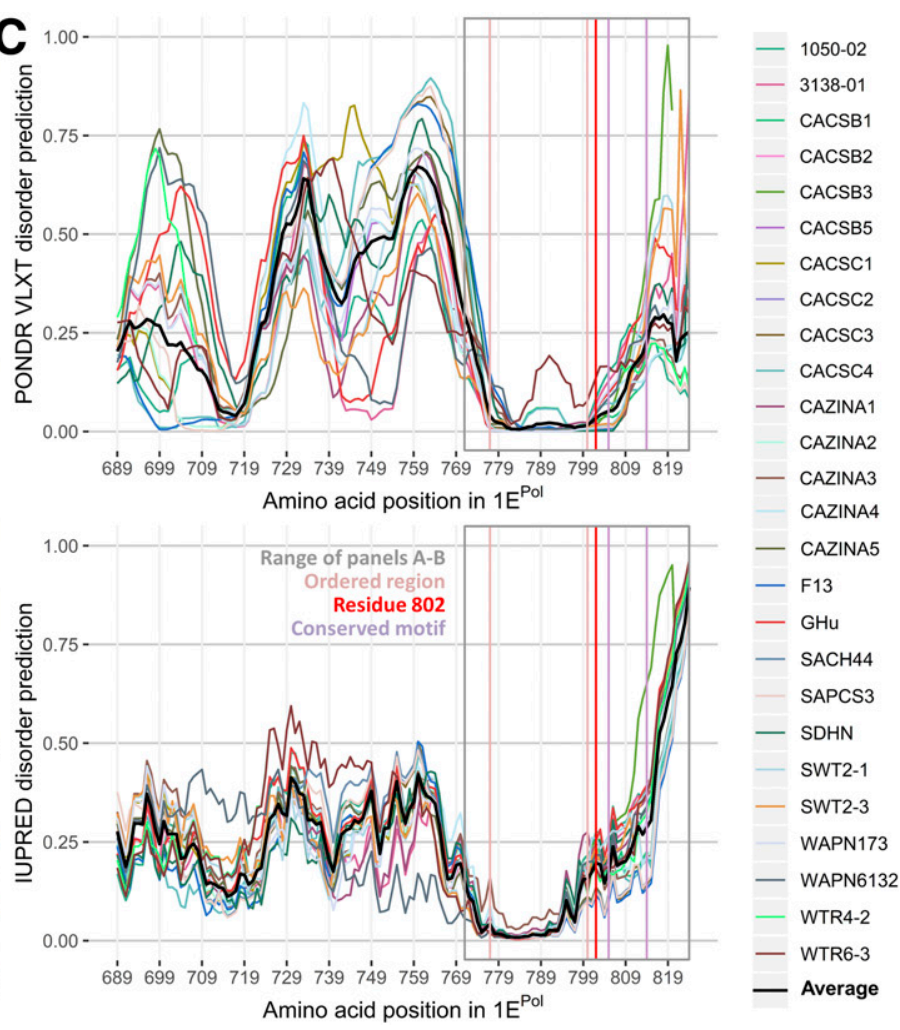

Fig. 3. In silico analyses of the $1 \mathrm{E}^{\mathrm{Pol}} \mathrm{C}$-terminus of grapevine fanleaf virus (GFLV) isolates. A, Alignment of the $1 \mathrm{E}^{\text {Pol }} \mathrm{C}$-terminus amino acid sequence (residues 771 to 824 ) of 26 GFLV isolates. Only residues differing from the GHu strain sequence (top line) are shown (a dot indicates a match to the GHu sequence). Residues unique to GFLV-GHu, identified as of December 2017, are highlighted by a gray arrow and are labeled with the residue number along the top. Residue 802, which is involved in symptom expression, is outlined in red. A sequence logo running along the bottom of the alignment provides an overview of the consensus sequence. The open pink box from residues 777 to 800 denotes the region predicted to be ordered by the PONDR VL-XT and IUPred programs for disorder prediction. The open lilac box from residue 805 to 814 indicates a highly conserved motif. B, PSSpred predictions of secondary structure of the $1 \mathrm{E}^{\mathrm{Pol}} \mathrm{C}$-terminus of GFLV-GHu and -F13. Color code for amino acid chemistry is the same in $\mathrm{A}$ and $\mathrm{B}$. C, Predictions of disorder for the C-terminus of $1 \mathrm{E}^{\mathrm{Pol}}$ of 26 GFLV isolates. Output of the PONDR VL-XT algorithm (top panel) and IUPred short order algorithm (bottom panel) for residues 681 to 824 of protein $1 \mathrm{E}^{\text {Pol }}$ In both plots, values $>0.5$ indicate disordered regions and values $<0.5$ indicate ordered (structured) regions. The thick black lines in both panels show the average prediction score across all shown isolates. The open gray box from residue 771 to 824 in both plots corresponds to the residues shown in A and B.

794 / Molecular Plant-Microbe Interactions 
coding region of the virus progeny confirmed that the K802E mutation was stably maintained in both the symptomatic plant and asymptomatic plants. Meanwhile, GHu K802N and $\mathrm{GHu}$ K802P (Fig. 2K to L) produced symptoms of vein clearing that were less severe than wild-type $\mathrm{GHu}$ and faded more rapidly (within 2 days of symptom development, compared with 5 to 8 days for wild-type $\mathrm{GHu}$ ). Mutation of this residue to arginine (R) or tyrosine (Y) as well as deletion of residue $S^{804}$ rendered the virus unable to systemically infect $N$. benthamiana following agroinoculation (Table 1). For all systemically infectious constructs, sequencing of virus progeny confirmed their fidelity, with no reversions to wild type or other substitutions detected. This work showed the nature of residue 802 of the $1 \mathrm{E}^{\mathrm{Pol}}$ protein of GFLV-GHu modulates expression of vein clearing in $N$. benthamiana.

\section{Residue 802 of the GFLV-GHu protein $1 \mathrm{E}^{\mathrm{Pol}}$ is flanked by strongly predicted secondary structures.}

Due to the difficulties of obtaining functional mutants in the $\mathrm{C}$-terminal region of the $1 \mathrm{E}^{\mathrm{Pol}}$ protein, we hypothesized that this region is highly structured, particularly the region flanking residue 802 . While tertiary structure prediction for $1 \mathrm{E}^{\mathrm{Pol}}$ via the iterative threading assembly refinement algorithm for protein structure prediction (I-TASSER) (Yang et al. 2015) produces a model with a good confidence score for the RdRp 'core' of this protein by threading the GFLV sequence onto solved RdRp structures, prediction of the C-terminus that includes the symptom determinant has a poor confidence score due to lack of homology to solved structures (data not shown). This leaves us with little insight into the actual tertiary structure of this region. Applying the protein secondary structure prediction algorithm (PSSpred), part of the I-TASSER suite, to predict the secondary structure of the C-terminus of protein $1 \mathrm{E}^{\mathrm{Pol}}$ of both GFLV strains GHu and F13, we showed that residues 807 to 812 of both proteins are predicted to be in a helix with $95 \%$ confidence (Fig. 3B). This putative helix lies within a 10residue motif ( ${ }^{805}$ LLKT/AHLK/RT/ALR ${ }^{814}$ ) of unknown function that is highly conserved among all GFLV isolates for which sequence information is available in the National Center for Biotechnology Information GenBank database (Fig. 3A). Additionally, the predictor of natural disordered regions (PONDR) VL-XT (Li et al. 1999) and the IUPred (prediction of intrinsically unstructured proteins) (Dosztányi et al. 2005) algorithms showed residues 777 to 800 to be ordered in GFLV strains GHu and F13 as well as in 24 other GFLV isolates, with high confidence, i.e., very low disorder prediction values. In contrast, no disordered regions were predicted with confidence (Fig. 3C). These in silico analyses indicated that residue 802 of the $1 \mathrm{E}^{\mathrm{Pol}}$ protein is flanked by strongly predicted stable secondary structures.

\section{Virus titer is not associated with GFLV-GHu symptomatology in $N$. benthamiana.}

We determined the relative GFLV titer of at least three plants per mutant by RT-quantitative (q)PCR, targeting GFLV RNA1 using specific primers (Fig. 4; Supplementary Table S2). In comparing the relative titers of mutants derived from GFLVGHu RNA1 to the wild-type strains GHu and F13, we detected no significant differences between any mutant pairs (one-way analysis of variance [ANOVA], $P=0.20$ ) or between the wildtype strain F13 and GHu (unpaired $t$ test, $P=0.36$ ). We also compared several F13-based mutants to the wild-type strains

Table 1. Grapevine fanleaf virus (GFLV) single and double amino acid mutants targeting the RNA1-encoded $1 \mathrm{E}^{\mathrm{Pol}}$ residues 802 and 804 and their behavior in Nicotiana benthamiana

\begin{tabular}{|c|c|c|c|c|c|c|c|}
\hline \multirow[b]{2}{*}{ Wild-type (WT) virus or construct name } & \multirow[b]{2}{*}{ RNA1 background } & \multicolumn{2}{|c|}{$\begin{array}{c}1 \mathrm{E}^{\mathrm{Pol}} \text { codon } \\
802\end{array}$} & \multicolumn{2}{|c|}{$\begin{array}{c}E^{P o l} \text { codon } \\
804\end{array}$} & \multirow[b]{2}{*}{ Systemic infection $^{\mathbf{a}}$} & \multirow[b]{2}{*}{ Symptoms ${ }^{b}$} \\
\hline & & NT & $\mathbf{A A}$ & NT & $\mathbf{A A}$ & & \\
\hline F13 (WT) & F13 & GGC & $\mathrm{G}$ & AAT & $\mathrm{N}$ & + & - \\
\hline GHu (WT) & $\mathrm{GHu}$ & AAG & $\mathrm{K}$ & AGC & $\mathrm{S}$ & + & + \\
\hline F13 G802K & F13 & AAG & $\mathrm{K}$ & AAT & $\mathrm{N}$ & + & - \\
\hline F13 G802G [C2406G] & F13 & GGG & $\mathrm{G}$ & AAT & $\mathrm{N}$ & + & - \\
\hline $\mathrm{F} 13 \mathrm{G} 802 \mathrm{~K}+\mathrm{N} 804 \mathrm{~S}$ & F13 & AAG & $\mathrm{K}$ & AGC & $\mathrm{S}$ & + & - \\
\hline $\mathrm{F} 13 \mathrm{G} 802 \mathrm{G}+\mathrm{N} 804 \mathrm{~N}$ & F13 & GGT & G & AAC & $\mathrm{N}$ & + & - \\
\hline F13 N804S & F13 & GGC & G & AGT & $\mathrm{S}$ & + & - \\
\hline F13 N804N [T2412C] & F13 & GGC & G & AAC & $\mathrm{N}$ & + & - \\
\hline GHu K802G & $\mathrm{GHu}$ & GGC & G & AGC & $\mathrm{S}$ & + & - \\
\hline GHu K802K [G2406A] & $\mathrm{GHu}$ & AAA & $\mathrm{K}$ & $\mathrm{AGC}$ & $\mathrm{S}$ & + & + \\
\hline GHu K802G+S804N & $\mathrm{GHu}$ & GGC & $\mathrm{G}$ & AAC & $\mathrm{N}$ & + & - \\
\hline GHu K802K+S804S & $\mathrm{GHu}$ & AAA & $\mathrm{K}$ & TCT & $\mathrm{S}$ & + & + \\
\hline GHu S804N & $\mathrm{GHu}$ & AAG & $\mathrm{K}$ & AAC & $\mathrm{N}$ & + & + \\
\hline GHu S804S [AGC to TCT] & $\mathrm{GHu}$ & AAG & $\mathrm{K}$ & TCT & $\mathrm{S}$ & + & + \\
\hline GHu K802A [GCC] & $\mathrm{GHu}$ & GCC & A & AGC & $\mathrm{S}$ & + & - \\
\hline GHu K802A [GCG] & $\mathrm{GHu}$ & GCG & A & AGC & $\mathrm{S}$ & + & - \\
\hline GHu K802Q & $\mathrm{GHu}$ & CAG & Q & AGC & $\mathrm{S}$ & + & - \\
\hline GHu K802E & $\mathrm{GHu}$ & GAG & $\mathrm{E}$ & AGC & $\mathrm{S}$ & + & Inconsistent $^{\mathrm{c}}$ \\
\hline GHu K802N & $\mathrm{GHu}$ & AAC & $\mathrm{N}$ & $\mathrm{AGC}$ & $\mathrm{S}$ & + & Weak ${ }^{\mathrm{d}}$ \\
\hline GHu K802P & $\mathrm{GHu}$ & CCG & $\mathrm{P}$ & AGC & $\mathrm{S}$ & + & Weak $^{\mathrm{d}}$ \\
\hline GHu K802R & $\mathrm{GHu}$ & CGT & $\mathrm{R}$ & AGC & $\mathrm{S}$ & - & N/A \\
\hline GHu K802Y & $\mathrm{GHu}$ & TAC & $\mathrm{Y}$ & AGC & $\mathrm{S}$ & - & N/A \\
\hline $\mathrm{GHu} \Delta \mathrm{S} 804$ & $\mathrm{GHu}$ & AAG & $\mathrm{K}$ & - & - & - & N/A \\
\hline F13 G802P & F13 & $\mathrm{CCC}$ & $\mathrm{P}$ & AAT & $\mathrm{N}$ & - & N/A \\
\hline
\end{tabular}

\footnotetext{
a Systemic infection (+) or lack thereof (-) was determined in apical leaves by double-antibody sandwich enzyme-linked immunosorbent assay using GFLVspecific antibodies 3 weeks after Agrobacterium tumefaciens-mediated inoculation. NT = nucleotides, AA = amino acid.

b Presence of vein clearing characteristic of wild-type GFLV-GHu (+) or lack thereof $(-)$ was assessed 1 to 2 weeks postinoculation. N/A = not applicable.

c This construct generally produced asymptomatic systemic infections. However, in a single mechanical inoculation experiment, one of the four systemically infected plants produced symptoms of vein clearing. Sequencing confirmed retention of the K802E mutation in both symptomatic and asymptomatic plants.

$\mathrm{d}$ These constructs produced weak symptoms of vein clearing that were fainter than those produced by wild-type GHu and faded more quickly (fading within 2 to 3 days of symptom development, compared with 5 to 8 days for wild type).
} 
and found no significant differences in relative GFLV RNA1 accumulation (one-way ANOVA, $P=0.10$ ). Altogether, RTqPCR did not reveal any significant difference in virus titer across mutants, as measured by RNA1 accumulation.

\section{Virus-induced gene silencing (VIGS) is not involved in GFLV-GHu $1 \mathrm{E}^{\mathrm{Pol}}$ symptom expression.}

While our results strongly suggested that the GFLV-GHu symptom determinant acts on a protein level, the silent mutation of residue 802 (GHu K802K [G2406A]) introduced only a single base change to the nt sequence of RNA1, a change possibly insufficient to abolish nt sequence complementarity to putative target host sequences. So, given mounting evidence that silencing of host genes via virus-derived small interfering RNAs plays a pivotal role in plant-virus pathogenesis (Zhang et al. 2015), we used VIGS to investigate the involvement of RNA silencing in GFLV-GHu vein clearing in $N$. benthamiana. We first introduced the full-length (408 nt) or small fragments (102 to $312 \mathrm{nt}$ ) of the GFLV-GHu $1 \mathrm{E}^{\mathrm{Pol}}$ symptom determinant region into a VIGS vector based on GFLV-GHu RNA2, known as $\mathrm{pG}_{\mathrm{R}}$ (Gottula 2014). The $\mathrm{pG}_{\mathrm{R}}$ plasmid contains a $B s i \mathrm{WI} / M l u \mathrm{I}$ cloning site between the $2 \mathrm{~A}^{\mathrm{HP}}$ and $2 \mathrm{~B}^{\mathrm{MP}}$ coding regions and a short polypeptide sequence (TYSSVIPNYSSSFIR/GEVPYVPEDG) immediately downstream of the cloning site for recognition by the GFLV $1 \mathrm{D}^{\text {Pro }}$ protease, allowing any inserted segments to be cleaved from the mature $2 \mathrm{~B}^{\mathrm{MP}}$ protein and to exist as a $\mathrm{C}$-terminal fusion of the $2 \mathrm{~A}^{\mathrm{HP}}$ protein. Fragments of the $\mathrm{GHu} 1 \mathrm{E}^{\mathrm{Pol}}$ coding region were cloned into this site as in-frame, reverse complement, or frameshift insertions (Supplementary Fig. S1). Results showed that none of the chimeric $\mathrm{pG}_{\mathrm{R}}$ constructs, regardless of their size and orientation, produced vein-clearing symptoms in $N$. benthamiana when paired with a GFLV-F13 RNA1 construct in replicated agroinoculation experiments of at least five plants each, although all of them were systemically infectious in $N$. benthamiana, as shown by DAS-ELISA. Sequencing of RNA2 of progeny viruses showed that all $\mathrm{pG}_{\mathrm{R}}$ constructs retained the inserted sequences, with no indels or substitutions. These findings suggested that the 408-nt symptom determinant previously identified (Vigne et al. 2013) does not cause vein clearing when expressed from GFLV-GHu RNA2.

To rule out the possibility that infection with GFLV-F13 RNA1 may somehow suppress or mask symptoms of vein clearing in $N$. benthamiana, we coinoculated $N$. benthamiana with F13 RNA1 and GHu RNA1 in the presence of GHu RNA2 via agroinoculation. These plants displayed typical symptoms of vein clearing on apical leaves. Both GFLV-F13 and GHu RNA1 were detected by RT-PCR with strain-specific primers in apical leaves followed by sequencing confirmation. We also tested whether $\mathrm{pG}_{\mathrm{R}}$ could be suppressive of vein clearing by agroinoculation of the empty $\mathrm{pG}_{\mathrm{R}}$ construct with GFLVGHu RNA1. This combination produced systemic infections displaying typical $\mathrm{GHu}$ vein clearing, indicating that $\mathrm{pG}_{\mathrm{R}}$ does not interfere with the development of vein clearing in $N$. benthamina. Furthermore, we confirmed that $\mathrm{pG}_{\mathrm{R}}$ is capable of inducing RNA silencing by using $\mathrm{pG}_{\mathrm{R}}-\mathrm{Nb}$ pds, which contains a 501-nt segment of $N$. benthamiana phytoene desaturase $(P D S)$ gene, with GFLV-F13 RNA1 in A. tumefaciensmediated inoculations. The resulting systemically infected plants displayed photobleaching symptoms typical of silencing of $P D S$, confirming the $\mathrm{pG}_{\mathrm{R}}$-based constructs are competent to induce gene silencing.

To further rule out the potential role of RNA silencing in $N$. benthamiana vein clearing, the GFLV $1 \mathrm{E}^{\mathrm{Pol}}$ symptom determinant sequence was introduced into a tobacco rattle virus (TRV) RNA2-based VIGS vector. While the GFLV VIGS assays utilized the full symptom determinant region, the TRV experiments focused on nt 2,404 to 2,424 of $1 \mathrm{E}^{\text {Pol }}$, which are involved in symptom development. Plants did not show GFLV$\mathrm{GHu}$ symptoms of vein clearing but typical TRV symptoms (stunting, mild mottling) and tested positive for TRV by RT-qPCR following A. tumefaciens-mediated inoculation in $N$. benthamiana. TRV:N.b.pds displayed photobleaching symptoms, as expected. To test whether GFLV-GHu symptoms

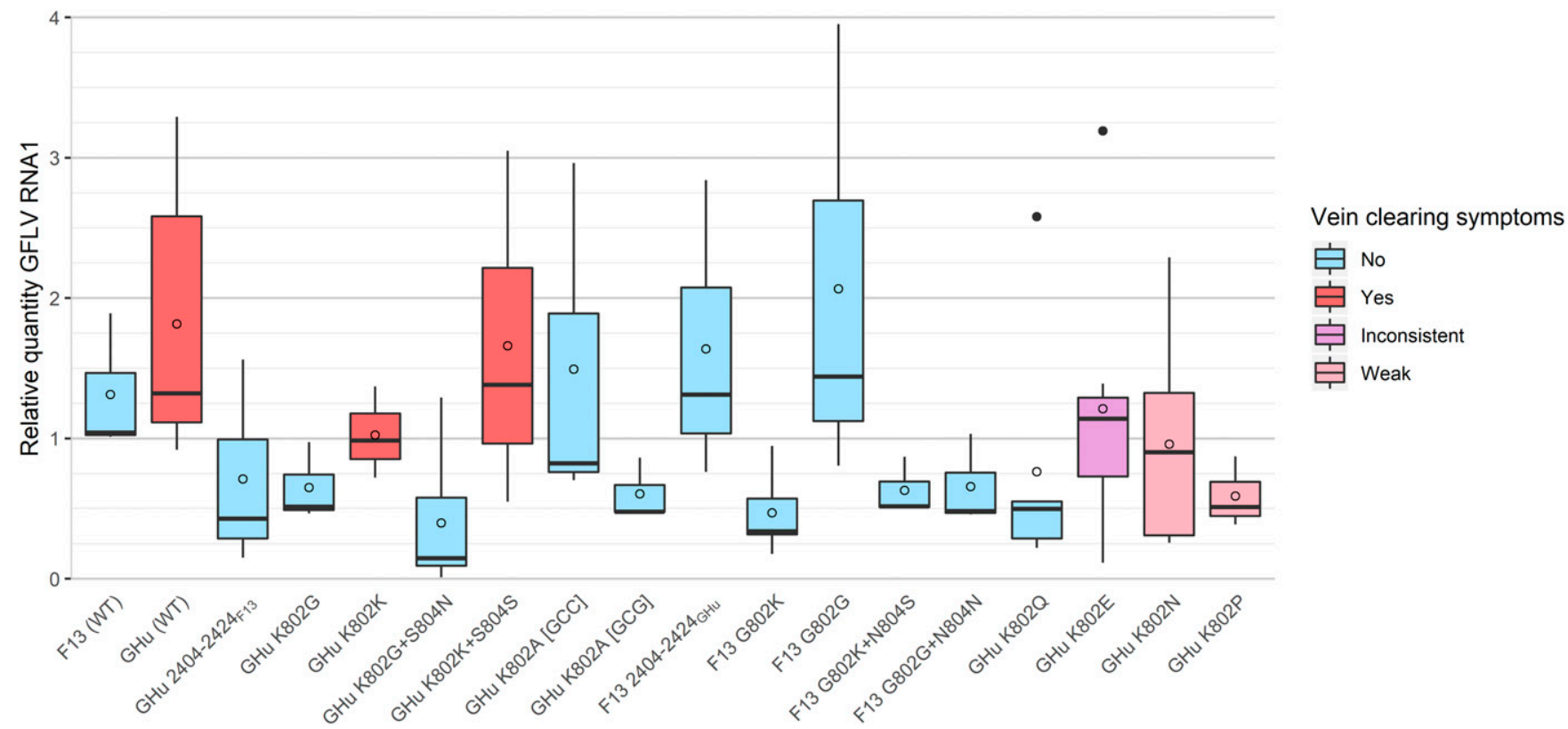

Fig. 4. Boxplot of relative titer of grapevine fanleaf virus (GFLV) wild-type (WT) strains F13 and GHu and GFLV $1 \mathrm{E}^{\mathrm{Pol}}$ mutants as determined by reverse transcription-quantitative polymerase chain reaction. Each box summarizes at least three biological replicates (plants) systemically infected with the same GFLV mutant or strain. The lower and upper hinges represent the 25th and 75th percentiles, respectively. Lower and upper whiskers show the smallest and largest values, respectively, with outliers (values more than 1.5 times the interquartile range beyond the hinge) shown as dots. The middle bar marks the median. Circles $(\bigcirc)$ superimposed on each box denote the mean. 
of vein clearing are dominant and distinguishable from TRV symptoms, TRV and GFLV-GHu were coinoculated via A. tumefaciens into $N$. benthamiana. Plants showed typical $\mathrm{GHu}$ symptoms starting 5 to 6 days postinoculation (dpi), then developed typical TRV symptoms (mottling and stunting) at 7 to 8 dpi. Plants were confirmed to be systemically coinfected with GFLV and TRV by DAS-ELISA and RT-qPCR, respectively. These findings showed that the introduction of the symptom determinant region of interest into a TRV vector did not cause vein clearing in N. benthamiana (Supplementary Fig. S2).

\section{DISCUSSION}

In investigating the nature of a symptom determinant responsible for vein clearing of GFLV strain $\mathrm{GHu}$ in $N$. benthamiana, we found that symptom development is dependent on the identity of the aa at position 802 of protein $1 \mathrm{E}^{\mathrm{Pol}}$. Symptoms of vein clearing develop when the native lysine $(\mathrm{K})$ is present at this position (Table 1; Fig. 2M to Y and CC), while substitution of this residue to glycine $(\mathrm{G}$, the native residue of GFLV-F13), alanine (A, the native residue of several GFLV isolates), or glutamine (Q) abolishes vein clearing (Table 1; Fig. $2 \mathrm{~F}$ to $\mathrm{H}$ and $\mathrm{J}$ ). Glutamic acid (E) in position 802 of protein $1 \mathrm{E}^{\mathrm{Pol}}$ produced inconsistent symptoms (Fig. 2BB; Table 1), while asparagine $(\mathrm{N})$ and proline $(\mathrm{P})$ produced weak symptoms (Table 1; Fig. 2K and L). These results, along with several other lines of evidence, suggest the involvement of a protein interaction between GFLV-GHu $1 \mathrm{E}^{\mathrm{Pol}}$ and $N$. benthamiana in the development of symptoms of vein clearing. Alternatively, the $\mathrm{K}$ residue may be involved in intramolecular interactions regulating $1 \mathrm{E}^{\mathrm{Pol}}$ structure.

Mutational analysis of the aa at position 802 yielded insights into the function of the $\mathrm{K}$ residue in that position for GFLV symptom expression. Substitution of proline at position 802 produced weak symptoms of vein clearing in $N$. benthamiana. However, proline is a nonpolar aa, like alanine and glycine, and has a unique cyclic structure in which the side chain forms a ring with the peptide backbone. This drastically reduces the rotational freedom of the backbone and this reduction in free entropy means proline is often found at 'turns' of a protein (Betts and Russell 2007). That the proline substitution mutant is able to produce symptoms, though weakly, favors the hypothesis that modulation of symptom development by this domain of $1 \mathrm{E}^{\mathrm{Pol}}$ is due to conformational changes to the $1 \mathrm{E}^{\mathrm{Pol}}$ protein influenced by the residue in this position rather than direct interaction between this residue and host plant proteins. This model contrasts with a study on cucumber green mottle mosaic virus in which single aa mutations to the methyltransferase domain of the viral RdRp produced symptom attenuation. Protein modeling of the methyltransferase domain showed the mutated residue to be surface exposed and aa replacements at this site appeared to have no effect on domain organization, suggesting the mutated residue may be modulating protein interactions necessary for symptom development without changes to the viral protein structure (Liu et al. 2017).

The seven canonical motifs of plant virus RdRps lie within the N-terminal 433 residues of protein $1 \mathrm{E}^{\mathrm{Pol}}$ (Ritzenthaler et al. 1991; Vigne et al. 2013), while the C-terminal region of $1 \mathrm{E}^{\mathrm{Pol}}$ bears no significant sequence homology to known sequences, apart from the RdRps of other nepoviruses (Vigne et al. 2013; this study). This illustrates the modular structures and multifunctionality of viral proteins (Leisner and Schoelz 2018; Valli et al. 2018). This dearth of homology also explains why tertiary structure prediction for $1 \mathrm{E}^{\mathrm{Pol}}$ via I-TASSER (Yang et al. 2015) produces a model with a good confidence score for the RdRp core of this protein, while structure prediction of the
C-terminus that includes the symptom determinant has a poor confidence score (data not shown). This leaves us with little insight into the actual tertiary structure of this region. Nonetheless, our study confirms earlier findings (Vigne et al. 2013) on the multifunctionality of protein $1 \mathrm{E}^{\mathrm{Pol}}$ with an implicated role in replication and a documented role in symptom development.

While de novo prediction of protein tertiary structure remains difficult, prediction of secondary structure from aa sequence alone can be done with a fair amount of accuracy. Thus, we were able to glean a few insights into the nature of the structure or structures surrounding residue 802 in GFLV-GHu $1 \mathrm{E}^{\mathrm{Pol}}$ by looking for evidence of stable secondary structures surrounding this aa. Both the IUPred and PONDR VL-XT algorithms strongly predict a highly ordered region from, approximately, residue 777 to 800 of $1 \mathrm{E}^{\mathrm{Pol}}$ in the 26 representative GFLV isolate sequences used for these analyses. Additionally, the PSSPred algorithm for secondary structure prediction, part of the I-TASSER suite (Yang et al. 2015), strongly predicts a helical structure for residues 807 to 812 of protein $1 \mathrm{E}^{\mathrm{Pol}}$ for both GFLVF13 and GFLV-GHu (Fig. 3B). This region lies within a 10-residue motif $\left({ }^{805}\right.$ LLKT/AHLK/RT/ALR $\left.{ }^{814}\right)$ of unknown function that is highly conserved among GFLV isolates for which sequence information is available in GenBank (Fig. 3A). The precise function of either of these predicted structured regions remains unknown. It is unsurprising to find symptom determinants within regions of virus proteins that lack functional annotation, such as the case of the highly-divergent $\mathrm{N}$ terminus of carlavirus cysteine-rich proteins (Fujita et al. 2018). The existence of two well-conserved motifs flanking residue 802 along with the knowledge that genetic manipulation of the C-terminus of GFLV $1 \mathrm{E}^{\mathrm{Pol}}$ often renders the virus unable to systemically infect $N$. benthamiana (Vigne et al. 2013; this study) provide further credence to the hypothesis that the identity of residue 802 determines the stability of a yet-to-be identified functional domain in the C-terminus of $1 \mathrm{E}^{\mathrm{Pol}}$.

Our work confirmed that symptoms of vein clearing in $N$. benthamiana are not correlated with overall virus titer or accumulation of $1 \mathrm{E}^{\mathrm{Pol}}$ (Vigne et al. 2013). While we acknowledge that RNA1 accumulation may be an incomplete proxy for $1 \mathrm{E}^{\text {Pol }}$ titer, given evidence in ToRSV, another nepovirus, that host responses to viral infection may repress translation without reducing RNA titer (Ghoshal and Sanfaçon 2014; Paudel et al. 2018), the earlier findings of Vigne et al. (2013) appear to hold true for the mutants produced for this study. There was no consistent pattern between GFLV RNA1 titer and mutant symptomatology (Fig. 4). While great strides have been recently made to advance our understanding of the mechanistic underpinnings of GFLV symptom expression in model host plants by documenting the role of proteins $1 \mathrm{E}^{\mathrm{Pol}}$ (Vigne et al. 2013; this study) and 2A ${ }^{\mathrm{HP}}$ (Martin et al. 2018), limited information is available on virus-host interactions in grapevine, the natural host. There have been attempts to correlate GFLV sequences and symptomatology in grapevine (Elbeaino et al. 2014), but no conclusions could be drawn on a specific symptom determinant. It is anticipated that reverse genetics approaches applied to model hosts will target grapevine in the future. Indeed, work is underway to transfer some of the mutants developed in this study to grapevine. It will be interesting to analyze, in the natural host of GFLV, the phenotype of these mutants and of the wild-type strains $\mathrm{GHu}$ and F13, which were originally isolated from diseased grapevines (Huss et al. 1989; Pinck et al. 1988) on which they cause a mild mosaic.

Lysine 802 of GFLV-GHu $1 \mathrm{E}^{\mathrm{Pol}}$ is indispensable but not sufficient for vein clearing in in $N$. benthamiana. Indeed, substituting glycine 802 with lysine in protein $1 \mathrm{E}^{\mathrm{Pol}}$ of the 
asymptomatic GFLV strain F13 (F13 G802K) is not sufficient to produce vein clearing in this strain (Table 1; Fig. 2B). It appears we do not yet have the full story of the GFLV-GHu symptom determinant; some component other than $1 \mathrm{E}^{\mathrm{Pol}}$ residue 802 must play a role in symptom development in $N$. benthamiana. While VIGS experiments ruled out a potential role of RNA silencing in GFLV-GHu symptom development, it is interesting to note that GFLV VIGS constructs bearing translatable portions of the $1 \mathrm{E}^{\mathrm{Pol}} \mathrm{C}$-terminus, including the region surrounding residue 802 , failed to elicit vein clearing in $N$. benthamiana. Thus, it appears that the GFLV-GHu symptom determinant is dependent on its native RNA1 context for its role in symptom development. Furthermore, there is precedent for a viral symptom determinant (modulator) and a viral symptom elicitor to be separate components. For example, Komatsu et al. (2011) found that both symptomatic and asymptomatic strains of plantago asiatica mosaic virus (PlAMV) encode a necrosisinducing form of the HEL domain of the RdRp; however, symptom development by PIAMV in $N$. benthamiana is dependent on RdRp accumulation, which is controlled by the POL domain of RdRp. More work is needed to address whether a similar situation applies to the GFLV-GHu $1 \mathrm{E}^{\mathrm{Pol}}$ protein.

Little is known of the molecular context of $1 \mathrm{E}^{\mathrm{Pol}}$ during GFLV infection, apart from its association with endoplasmic reticulum membranes that are the site of nepovirus replication (Fuchs et al. 2017; Ritzenthaler et al. 2002). Further work, such as structural determination using nuclear magnetic resonance spectroscopy or X-ray crystallography and, perhaps, coimmunoprecipitation of $1 \mathrm{E}^{\mathrm{Pol}}$ and mass spectroscopy identification of protein interactors are needed to determine what other viral or host components are involved in GFLV development of vein clearing in $N$. benthamiana.

\section{MATERIALS AND METHODS}

\section{In silico characterization of GFLV $1 \mathrm{E}^{\mathrm{Pol}}$.}

The nt sequences of GFLV isolates, which included sequence data for the $3^{\prime}$ ultimate $408 \mathrm{nt}$ of the $1 \mathrm{E}^{\mathrm{Pol}}$ coding region, were retrieved from GenBank, as of December 2017, along with the predicted translation sequences of $1 \mathrm{E}^{\mathrm{Pol}}$. Sequences were manually trimmed to include only the $408 \mathrm{nt}$ and 136 aa of interest. A recent metagenomic study provided 70 new complete GFLV RNA1 sequences to GenBank (Hily et al. 2018). We selected four representative sequences from this set for inclusion in our in silico analyses. The full list and reference information of GFLV isolates used for in silico analyses is provided in Supplementary Table S3.

To identify potential disordered regions, the trimmed polyprotein sequences were run through the PONDR VL-XT (Li et al. 1999; Romero et al. 2001) and the IUPred (Dosztányi et al. 2005) algorithms. Since both programs treat termini differently than internal sequences, the sequences for all isolates were extended to include 8 aa upstream of the $136 \mathrm{C}$-terminal aa (i.e., predictions were run on residues 681 to 824 rather than 689 to 824) such that residues 689 and beyond were treated as internal rather than terminal residues. Residues 689 to 824 of GFLV-GHu $1 \mathrm{E}^{\mathrm{Pol}}$ were used in the Simple Modular Architecture Research Tool to search for putative functional protein motifs or domains within this region of the $1 \mathrm{E}^{\mathrm{Pol}}$ protein. For protein modeling, the complete aa sequence of the $1 \mathrm{E}^{\mathrm{Pol}}$ coding region for GFLV-GHu along with truncated sequences of residues 1 to 520 and 520 to 824 were run through I-TASSER (Yang et al. 2015), using the default settings.

\section{Creation of chimeric and mutant GFLV RNA1 constructs.}

Each GFLV RNA1 mutant construct used in A. tumefaciensmediated inoculation (agroinoculation) assays was generated, using pCLEAN-GHu-1, pCLEAN-F13-1, or derivatives thereof (Osterbaan et al. 2018) as templates for site-directed mutagenesis, using the Q5 site-directed mutagenesis kit (New England Biolabs) as per manufacturer instructions, with specific back-toback primers designed using the NEBaseChanger software (v. 1.2.6). Plasmids pCLEAN-GHu-1 and pCLEAN-F13-1 contain the full-length cDNA of GFLV-GHu and GFLV-F13 RNA1, respectively. Expression of the GFLV RNA1 cDNAs in pCLEAN is driven by the cauliflower mosaic virus $35 \mathrm{~S}$ promoter and terminator sequences. Chimeric plasmids from single colonies were screened for proper mutations by Sanger sequencing, with primers specific to the region of interest, at Cornell University Biotechnology Resource Center. At least one successfully mutated plasmid clone of each construct was selected for in planta characterization by agroinoculation. All primers used for construct and viral progeny sequencing confirmation, including those for TRV and $\mathrm{pG}_{\mathrm{R}}$ constructs can be found in Supplementary Table S4.

Constructs used in mechanical inoculation with in-vitro RNA transcripts were generated by site-directed mutagenesis with overlap PCR (Hemsley et al. 1989) using $\mathrm{pF} 1_{\mathrm{S}}$ (Vigne et al. 2013) as a template, and mutagenic primers. Plasmid $\mathrm{pF} 1_{\mathrm{S}}$ contains the full-length cDNA of GFLV-F13 RNA1 slightly modified by the insertion of a SnaBI site (Vigne et al. 2013). Expression of the GFLV-F13 RNA1 is driven by the T7 promoter. For each construct, three PCRs were performed with Phusion high-fidelity DNA polymerase (New England Biolabs). In the first PCR, the forward mutagenic primer was paired with primer EVP1R7854; in the second PCR, the reverse mutagenic primer was paired with primer EV1SGFsn4628; in the third PCR, the products of the first two reactions were combined and amplified by the primer pair EV1SFGsn4628/EVP1R7854. The resulting amplicon was then cloned into the $\mathrm{pF} 1_{\mathrm{S}}$ backbone by SnaBI/NotI digestion and ligation. Supplementary Table S5 lists all primers used for mutagenesis and cloning, including those used for cloning into TRV and $\mathrm{pG}_{\mathrm{R}}$ VIGS constructs.

\section{Creation of TRV and GFLV RNA2 VIGS constructs.}

For VIGS experiments, all $\mathrm{pG}_{\mathrm{R}}$ constructs were generated by amplification of regions of the GFLV-GHu symptom determinant region from pCLEAN-GHu-1 using specific primers. The $\mathrm{pG}_{\mathrm{R}}$ plasmid contains a $B s i \mathrm{WI} / \mathrm{MluI}$ cloning site between the $2 \mathrm{~A}^{\mathrm{HP}}$ and $2 \mathrm{~B}^{\mathrm{MP}}$ coding regions and a short peptide sequence (TYSSVIPNYSSSFIR/GEVPYVPEDG), immediately downstream of the cloning site, that is recognized by the GFLV $1 \mathrm{D}^{\text {Pro }}$ protease, allowing any inserted segments to be cleaved from the mature $2 \mathrm{~B}^{\mathrm{MP}}$ protein and to exist as a $\mathrm{C}$-terminal fusion of the $2 \mathrm{~A}^{\mathrm{HP}}$ protein (Gottula 2014). For cloning purposes, the symptom determinant region was expanded to include $24 \mathrm{nt}$ upstream of the $3^{\prime}$ ultimate $408 \mathrm{nt}$ of the $1 \mathrm{E}^{\mathrm{Pol}}$ coding region (thus, fragments were selected from the $3^{\prime}$ ultimate $432 \mathrm{nt}$ ). Amplicons were digested with one or both $B s i \mathrm{WI}$ and $M l u \mathrm{I}$ and were ligated into $\mathrm{pG}_{\mathrm{R}}$. Plasmids from single colonies were screened for successful insertion by sequencing with specific primers flanking the insertion site.

To generate constructs for TRV-based VIGS, primers with Gateway attB sites were designed to amplify a 191-bp fragment from the full-length cDNAs of GFLV-F13 and GFLV-GHu RNA1 clones at nt position 6,951 to 7,141 (specifically, nt 2,329 to 2,475 of the $1 \mathrm{E}^{\mathrm{Pol}}$ coding region plus the first $44 \mathrm{nt}$ of the $3^{\prime}$ untranslated region). The attB2 reverse primer was used for both the TRV:1 $1 \mathrm{E}_{\mathrm{F} 13}$ and TRV: $1 \mathrm{E}_{\mathrm{GHu}}$ clones. Fragments were cloned into a Gateway-compatible version of the pTRV2 expression vector (Liu et al. 2002a and b), using Gateway cloning technology (Invitrogen). Clones were confirmed by sequencing and were mobilized into A. tumefaciens GV3101. The negative control vector TRV:GFP was generated 
by cloning a green fluorescent protein fragment into the pTRV2 expression vector (Kandoth et al. 2007).

\section{Agrobacterium tumefaciens-mediated inoculation and characterization of GFLV chimeras and mutants in $N$. benthamiana.}

GFLV RNA1 chimeras and mutants were paired with a wildtype GFLV-GHu RNA2 and were used for A. tumefaciensmediated inoculation as previously described (Osterbaan et al. 2018). Wild-type GHu RNA1 and F13 RNA1 constructs were inoculated in parallel with GFLV-GHu RNA2 for each agroinoculation experiment.

Chimeras and mutants were considered infectious if the majority of the plants used in at least two independent A. tumefaciens-mediated inoculation (agroinoculation) experiments of at least five $N$. benthamiana plants each became systemically infected with GFLV by 3 weeks postinoculation, as determined by DAS-ELISA using specific antibodies (Bioreba). In the rare occurrence of less than half of the agroinoculated $N$. benthamiana plants becoming systemically infected by 3 weeks postinoculation, as shown by DAS-ELISA, the virus was mechanically passaged from the initially infected $N$. benthamiana onto leaves of 4 -week-old $N$. benthamiana plants lightly dusted with Carborundum by rubbing crude sap of infected tissue ground 1:5 (wt/vol) in phosphate buffer (35 mM Na $2 \mathrm{HPO}_{4}, 15 \mathrm{mM} \mathrm{KH} \mathrm{KO}_{4}, \mathrm{pH}$ 7.0). Chimeras and mutants were considered unable to systemically infect $N$. benthamiana if none of the plants used in at least two independent agroinoculation experiments of at least five $N$. benthamiana plants each became systemically infected with GFLV by 3 weeks postinoculation, as determined by DASELISA.

Mutants were considered symptomatic if all infected $N$. benthamiana plants displayed symptoms of vein clearing that were visually indistinguishable from those produced by a parallel wild-type GFLV-GHu control. Mutants were considered weakly symptomatic if, in at least two independent inoculations (agroinoculation or mechanical inoculation), all infected $N$. benthamiana plants displayed less distinct symptoms of vein clearing that were visually similar to but faded more quickly than those of a parallel wild-type $\mathrm{GHu}$ control. Mutants were considered inconsistently symptomatic if there was a mixture of symptomatic and asymptomatic plants among those plants that became infected.

For VIGS assays, all $\mathrm{pG}_{\mathrm{R}}$ constructs were paired with wildtype GFLV-F13 RNA1 for agroinoculation. Control inoculations were the wild-type GFLV-GHu RNA1 paired with the empty $\mathrm{pG}_{\mathrm{R}}$ plasmid (positive control for development of veinclearing symptoms) and F13 RNA1 paired with $\mathrm{pG}_{\mathrm{R}}-\mathrm{Nb}$-pds (positive control for virus-induced gene silencing that produces photobleaching symptoms due to silencing of $N$. benthamiana $P D S) . N$. benthamiana plants were agroinoculated with TRV: $1 \mathrm{E}_{\mathrm{F} 13}$ or TRV:1 $\mathrm{E}_{\mathrm{GHu}}$ by mixing cultures (optical density at $600 \mathrm{~nm}=1.0$ ) of chimeric pTRV2 1:1 with pTRV1 (Liu et al. 2002a).

At least two independent A. tumefaciens-mediated inoculation experiments of at least five plants each were conducted for chimeric and mutant GFLV RNA1 constructs in this study in the presence of GFLV GHu RNA2. Agroinoculated $N$. benthamiana were maintained at $25^{\circ} \mathrm{C}$ in growth chambers (16-h light cycle) and were monitored for symptom development. Plants were photographed (Nikon D40, Nikkor AF-S DX micro 85-mm lens, growth chamber lighting) once typical symptoms of vein clearing developed. In the case of asymptomatic constructs, plants were photographed once symptoms of vein clearing developed in the wild-type $\mathrm{GHu}$ or photobleaching symptoms developed in $\mathrm{pG}_{\mathrm{R}}-\mathrm{Nb}$-pds control treatments. Apical leaves were collected at 3 weeks postinoculation and were used to detect systemic GFLV infection by DAS-ELISA, using specific antibodies (Bioreba). Samples were recorded as positive if the absorbances values at $405 \mathrm{~nm}$ of duplicate wells were greater than three times the average absorbance values of the negative control samples (healthy $N$. benthamiana tissue of commensurate age). To confirm the fidelity of the virus progeny, total RNA was extracted from apical leaves at 4 weeks postinoculation (E.Z.N.A. plant RNA kit) and was used for RT-PCR (Qiagen OneStep) with specific primers. DNA products of RT-PCR were sequenced at Cornell University Biotechnology Resource Center and were matched to the original constructs using the SeqManPro program of the DNASTAR/Lasergene (v. 15) molecular biology software package.

\section{Mechanical inoculation with in-vitro RNA transcripts and characterization of virus progeny in $N$. benthamiana.}

In-vitro RNA transcripts of $\mathrm{pF} 1_{\mathrm{S}}$ derivatives were prepared, along with transcripts of GFLV-F13 RNA2, as described in Vigne et al. (2013), and were used to mechanically inoculate Chenopodium quinoa plants. Tissue from systemically infected C. quinoa plants was used as inoculum for mechanical passage to $N$. benthamiana. Infection was determined by DAS-ELISA using specific antibodies (Bioreba) and symptoms of vein clearing were monitored on infected $N$. benthamiana. Fidelity of progeny viruses was confirmed by sequencing immunocaptureRT-PCR products of crude extracts of apical leaves, using primer pairs G9/G10, G11/G12, G13/G14, and G15/16.

\section{Confirmation of TRV infection by RT-qPCR.}

Apical tissue of $N$. benthamiana plants inoculated via A. tumefaciens was collected $17 \mathrm{dpi}$, was flash-frozen in liquid nitrogen, and was stored at $-80^{\circ} \mathrm{C}$ until RNA extraction. RNA extraction, cDNA synthesis, and primer sets were as previously described (DeBlasio et al. 2018). qPCR for assessing TRV infection was performed with PowerSYBR green master mix on a QuantStudio 6 Flex 384-well system. Thermocycling conditions were $95^{\circ} \mathrm{C}$ for $20 \mathrm{~s}, 95^{\circ} \mathrm{C}$ for $1 \mathrm{~s}$, and $60^{\circ} \mathrm{C}$ for $20 \mathrm{~s}$ ( 40 cycles).

\section{Determination of GFLV titer by RT-qPCR and statistical analysis.}

Four-week-old $N$. benthamiana plants were mechanically inoculated with GFLV wild-type and mutant strains. Tissue from apical leaves was collected 13 dpi for total RNA extraction (E.Z.N.A. plant RNA kit). This timepoint was chosen to align with that used by Vigne et al. (2013) for the quantification of GFLV by semiquantitative DAS-ELISA. Total RNA was treated with amplification grade DNAse I (Invitrogen) and was converted to cDNA using Superscript IV VILO MasterMix (Invitrogen). qPCR was performed with iTaq Universal SYBR green supermix (Bio-Rad) and primers specific to GFLV RNA1 and three plant reference genes (actin, cyclin-dependent kinase, and elongation factor $1 \alpha$ ) with three technical replicates per sample per target (Supplementary Table S6) on a Bio-Rad CFX96 Touch thermocycler. Thermocycling conditions were $95^{\circ} \mathrm{C}$ for $3 \mathrm{~min}, 95^{\circ} \mathrm{C}$ for $10 \mathrm{~s}$, and $60^{\circ} \mathrm{C}$ for $30 \mathrm{~s}$ (40 cycles). Calibrated normalized relative quantity (CNRQ) of GFLV RNA1 was calculated in qbase+ (Biogazelle) by comparison of GFLV $\triangle \mathrm{Cq}$ (quantification cycle) values normalized against the three reference genes (Vandesompele et al. 2002) and calibrated against an interrun calibrator sample, which was included in every run (Hellemans et al. 2007). The qbase+ program uses the geNorm algorithm to calculate the stability of the reference genes ( $\mathrm{M}$ value). The $\mathrm{M}$ values for actin, cyclin-dependent $\mathrm{ki}$ nase, and elongation factor $1 \alpha$ in this study were $0.69,0.87$, and 0.69 , respectively. CNRQ values were imported into $\mathrm{R}$ and 
one-way ANOVA (for comparison of F13-based mutants and GHu-based mutants to wild-type strains) or $t$ test (comparison of wild-type strains F13 and $\mathrm{GHu}$ ) were performed on untransformed CNRQ values.

\section{ACKNOWLEDGMENTS}

We thank P. Marsella-Herrick and M. Cheung for technical assistance and $\mathrm{J}$. Gottula for inspiring the $\mathrm{pG}_{\mathrm{R}}$ experiments. Thanks are also due to $\mathrm{K}$ Cox and D. Strickland for guidance on statistical analyses, J. Wilson for advice on visual data presentation, and to J.-M. Hily for guidance in selecting GFLV isolates for comparative analyses.

\section{LITERATURE CITED}

Betts, M. J., and Russell, R. B. 2007. Amino-acid properties and consequences of substitutions. Pages 311-342 in: Bioinformatics for Geneticists. M. R. Barnes, ed. John Wiley \& Sons, Ltd, Chichester, U.K.

Culver, J. N., and Padmanabhan, M. S. 2007. Virus-induced disease: Altering host physiology one interaction at a time. Annu. Rev. Phytopathol. 45:221-243.

DeBlasio, S. L., Rebelo, A. R., Parks, K., Gray, S. M., and Heck, M. C. 2018. Disruption of chloroplast function through downregulation of phytoene desaturase enhances the systemic accumulation of an aphid-borne, phloem-restricted virus. Mol. Plant-Microbe Interact. 31:1095-1110.

Digiaro, M., Elbeaino, T., and Martelli, G. P. 2017. Grapevine fanleaf virus and other Old World nepoviruses. Pages 47-82 in: Grapevine Viruses: Molecular Biology, Diagnostics and Management. B. Meng, G. P. Martelli, D. A. Golino, and M. Fuchs, eds. Springer International Publishing, Cham, Switzerland.

Dosztányi, Z., Csizmok, V., Tompa, P., and Simon, I. 2005. IUPred: Web server for the prediction of intrinsically unstructured regions of proteins based on estimated energy content. Bioinformatics 21:3433-3434.

Duff-Farrier, C. R. A., Bailey, A. M., Boonham, N., and Foster, G. D. 2015. A pathogenicity determinant maps to the N-terminal coat protein region of the Pepino mosaic virus genome. Mol. Plant Pathol. 16:308-315.

Elbeaino, T., Kiyi, H., Boutarfa, R., Minafra, A., Martelli, G. P., and Digiaro, M. 2014. Phylogenetic and recombination analysis of the homing protein domain of grapevine fanleaf virus (GFLV) isolates associated with 'yellow mosaic' and 'infectious malformation' syndromes in grapevine. Arch. Virol. 159:2757-2764.

Fuchs, M., Schmitt-Keichinger, C., and Sanfaçon, H. 2017. A renaissance in nepovirus research provides new insights into their molecular interface with hosts and vectors. Pages 61-105 in: Advances in Virus Research. M. Kielian, T. C. Mettenleiter, and M. J. Roossinck, eds. Academic Press, Cambridge, MA, U.S.A.

Fujita, N., Komatsu, K., Ayukawa, Y., Matsuo, Y., Hashimoto, M., Netsu, O., Teraoka, T., Yamaji, Y., Namba, S., and Arie, T. 2018. N-terminal region of cysteine-rich protein (CRP) in carlaviruses is involved in the determination of symptom types. Mol. Plant Pathol. 19:180-190.

García, J. A., and Pallás, V. 2015. Viral factors involved in plant pathogenesis. Curr. Opin. Virol. 11:21-30.

Ghoshal, B., and Sanfaçon, H. 2014. Temperature-dependent symptom recovery in Nicotiana benthamiana plants infected with tomato ringspot virus is associated with reduced translation of viral RNA2 and requires ARGONAUTE 1. Virology 456-457:188-197.

Gottula, J. W. 2014. Grapevine fanleaf virus: biology, biotechnology and resistance. Doctoral thesis. Cornell University, Ithaca, NY, U.S.A.

Hasiów-Jaroszewska, B., Borodynko, N., Jackowiak, P., Figlerowicz, M., and Pospieszny, H. 2011. Single mutation converts mild pathotype of the Pepino mosaic virus into necrotic one. Virus Res. 159:57-61.

Hasiów-Jaroszewska, B., Paeleman, A., Ortega-Parra, N., Borodynko, N., Minicka, J., Czerwoniec, A., Thomma, B. P. H. J., and Hanssen, I. M. 2013. Ratio of mutated versus wild-type coat protein sequences in Pepino mosaic virus determines the nature and severity of yellowing symptoms on tomato plants. Mol. Plant Pathol. 14:923-933.

Heaton, L. A., Lee, T. C., Wei, N., and Morris, T. J. 1991. Point mutations in the turnip crinkle virus capsid protein affect the symptoms expressed by Nicotiana benthamiana. Virology 183:143-150.

Hellemans, J., Mortier, G., De Paepe, A., Speleman, F., and Vandesompele, J. 2007. qBase relative quantification framework and software for management and automated analysis of real-time quantitative PCR data. Genome Biol. 8:R19.

Hemsley, A., Arnheim, N., Toney, M. D., Cortopassi, G., and Galas, D. J. 1989. A simple method for site-directed mutagenesis using the polymerase chain reaction. Nucleic Acids Res. 17:6545-6551.
Hily, J.-M., Demanèche, S., Poulicard, N., Tannières, M., Djennane, S., Beuve, M., Vigne, E., Demangeat, G., Komar, V., Gertz, C., Marmonier, A., Hemmer, C., Vigneron, S., Marais, A., Candresse, T., Simonet, P., and Lemaire, O. 2018. Metagenomic-based impact study of transgenic grapevine rootstock on its associated virome and soil bacteriome. Plant Biotechnol. J. 16:208-220.

Huss, B., Walter, B., and Fuchs, M. 1989. Cross-protection between arabis mosaic virus and grapevine fan leaf virus isolates in Chenopodium quinoa. Ann. Appl. Biol. 114:45-60.

Kagiwada, S., Yamaji, Y., Komatsu, K., Takahashi, S., Mori, T., Hirata, H., Suzuki, M., Ugaki, M., and Namba, S. 2005. A single amino acid residue of RNA-dependent RNA polymerase in the Potato virus $X$ genome determines the symptoms in Nicotiana plants. Virus Res. 110:177-182.

Kandoth, P. K., Ranf, S., Pancholi, S. S., Jayanty, S., Walla, M. D., Miller, W., Howe, G. A., Lincoln, D. E., and Stratmann, J. W. 2007. Tomato MAPKs LeMPK1, LeMPK2, and LeMPK3 function in the systeminmediated defense response against herbivorous insects. Proc. Natl. Acad. Sci. U.S.A. 104:12205-12210.

Karran, R. A., and Sanfaçon, H. 2014. Tomato ringspot virus coat protein binds to ARGONAUTE 1 and suppresses the translation repression of a reporter gene. Mol. Plant-Microbe Interact. 27:933-943.

Komatsu, K., Hashimoto, M., Maejima, K., Shiraishi, T., Neriya, Y., Miura, C., Minato, N., Okano, Y., Sugawara, K., Yamaji, Y., and Namba, S. 2011. A necrosis-inducing elicitor domain encoded by both symptomatic and asymptomatic Plantago asiatica mosaic virus isolates, whose expression is modulated by virus replication. Mol. Plant-Microbe Interact. 24:408-420.

Leisner, S. M., and Schoelz, J. E. 2018. Joining the crowd: Integrating plant virus proteins into the larger world of pathogen effectors. Annu. Rev. Phytopathol. 56:89-110.

Li, X., Romero, P., Rani, M., Dunker, A. K., and Obradovic, Z. 1999. Predicting protein disorder for N-, C-, and internal regions. Genome Inform. Ser. Workshop Genome Inform. 10:30-40.

Liu, L., Peng, B., Zhang, Z., Wu, Y., Miras, M., Aranda, M. A., and Gu, Q. 2017. Exploring different mutations at a single amino acid position of Cucumber green mottle mosaic virus replicase to attain stable symptom attenuation. Phytopathology 107:1080-1086.

Liu, Y., Schiff, M., and Dinesh-Kumar, S. P. 2002a. Virus-induced gene silencing in tomato. Plant J. 31:777-786.

Liu, Y., Schiff, M., Marathe, R., and Dinesh-Kumar, S. P. 2002b. Tobacco Rarl, EDS1 and NPRI/NIM1 like genes are required for $N$-mediated resistance to tobacco mosaic virus. Plant J. 30:415-429.

Mansilla, C., Sánchez, F., Padgett, H. S., Pogue, G. P., and Ponz, F. 2009. Chimeras between Oilseed rape mosaic virus and Tobacco mosaic virus highlight the relevant role of the tobamoviral $R d R p$ as pathogenicity determinant in several hosts. Mol. Plant Pathol. 10:59-68.

Martin, I. R., Vigne, E., Berthold, F., Komar, V., Lemaire, O., Fuchs, M., and Schmitt-Keichinger, C. 2018. The 50 distal amino acids of the $2 \mathrm{~A}^{\mathrm{HP}}$ homing protein of Grapevine fanleaf virus elicit a hypersensitive reaction on Nicotiana occidentalis. Mol. Plant Pathol. 19:731-743.

Osterbaan, L. J., Schmitt-Keichinger, C., Vigne, E., and Fuchs, M. 2018. Optimal systemic grapevine fanleaf virus infection in Nicotiana benthamiana following agroinoculation. J. Virol. Methods 257:16-21.

Ozeki, J., Takahashi, S., Komatsu, K., Kagiwada, S., Yamashita, K., Mori, T., Hirata, H., Yamaji, Y., Ugaki, M., and Namba, S. 2006. A single amino acid in the RNA-dependent RNA polymerase of Plantago asiatica mosaic virus contributes to systemic necrosis. Arch. Virol. 151: 2067-2075.

Padmanabhan, M. S., Goregaoker, S. P., Golem, S., Shiferaw, H., and Culver, J. N. 2005. Interaction of the tobacco mosaic virus replicase protein with the Aux/IAA protein PAP1/IAA26 is associated with disease development. J. Virol. 79:2549-2558.

Paudel, D. B., Ghoshal, B., Jossey, S., Ludman, M., Fatyol, K., and Sanfaçon, H. 2018. Expression and antiviral function of ARGONAUTE 2 in Nicotiana benthamiana plants infected with two isolates of tomato ringspot virus with varying degrees of virulence. Virology 524:127-139.

Pinck, L., Fuchs, M., Pinck, M., Ravelonandro, M., and Walter, B. 1988. A satellite RNA in grapevine fanleaf virus strain F13. J. Gen. Virol. 69: 233-239.

Qiu, Y., Zhang, Y., Wang, C., Lei, R., Wu, Y., Li, X., and Zhu, S. 2018. Cucumber mosaic virus coat protein induces the development of chlorotic symptoms through interacting with the chloroplast ferredoxin I protein. Sci. Rep. 8:1205.

Rao, A. L. N., and Grantham, G. L. 1995. A spontaneous mutation in the movement protein gene of brome mosaic virus modulates symptom phenotype in Nicotiana benthamiana. J. Virol. 69:2689-2691.

Ritzenthaler, C., Laporte, C., Gaire, F., Dunoyer, P., Schmitt, C., Duval, S., Piéquet, A., Loudes, A.-M., Rohfritsch, O., Stussi-Garaud, C., and 
Pfeiffer, P. 2002. Grapevine fanleaf virus replication occurs on endoplasmic reticulum-derived membranes. J. Virol. 76:8808-8819.

Ritzenthaler, C., Viry, M., Pinck, M., Margis, R., Fuchs, M., and Pinck, L. 1991. Complete nucleotide sequence and genetic organization of grapevine fanleaf nepovirus RNA1. J. Gen. Virol. 72:2357-2365.

Rodríguez-Cerezo, E., Klein, P. G., and Shaw, J. G. 1991. A determinant of disease symptom severity is located in the $3^{\prime}$-terminal noncoding region of the RNA of a plant virus. Proc. Natl. Acad. Sci. U.S.A. 88:9863-9867.

Romero, P., Obradovic, Z., Li, X., Garner, E. C., Brown, C. J., and Dunker, A. K. 2001. Sequence complexity of disordered protein. Proteins 42:38-48.

Schmitt-Keichinger, C., Hemmer, C., Berthold, F., and Ritzenthaler, C. 2017. Molecular, Cellular, and Structural Biology of Grapevine fanleaf virus. Pages 83-107 in: Grapevine Viruses: Molecular Biology, Diagnostics and Management. B. Meng, G. P. Martelli, D. A. Golino, and M. Fuchs, eds. Springer International Publishing, Cham.

Shiboleth, Y. M., Haronsky, E., Leibman, D., Arazi, T., Wassenegger, M., Whitham, S. A., Gaba, V., and Gal-On, A. 2007. The conserved FRNK box in HC-Pro, a plant viral suppressor of gene silencing, is required for small RNA binding and mediates symptom development. J. Virol. 81: 13135-13148.

Shimura, H., Pantaleo, V., Ishihara, T., Myojo, N., Inaba, J., Sueda, K., Burgyán, J., and Masuta, C. 2011. A viral satellite RNA induces yellow symptoms on tobacco by targeting a gene involved in chlorophyll biosynthesis using the RNA silencing machinery. PLoS Pathog. 7: e1002021.

Smith, N. A., Eamens, A. L., and Wang, M.-B. 2011. Viral small interfering RNAs target host genes to mediate disease symptoms in plants. PLoS Pathog. 7:e1002022.
Valli, A. A., Gallo, A., Rodamilans, B., López-Moya, J. J., and García, J. A. 2018. The HCPro from the Potyviridae family: An enviable multitasking helper component that every virus would like to have. Mol. Plant Pathol. 19:744-763.

Vandesompele, J., De Preter, K., Pattyn, F., Poppe, B., Van Roy, N., De Paepe, A., and Speleman, F. 2002. Accurate normalization of real-time quantitative RT-PCR data by geometric averaging of multiple internal control genes. Genome Biol. 3:research0034.1.

Vigne, E., Gottula, J., Schmitt-Keichinger, C., Komar, V., Ackerer, L., Belval, L., Rakotomalala, L., Lemaire, O., Ritzenthaler, C., and Fuchs, M. 2013. A strain-specific segment of the RNA-dependent RNA polymerase of grapevine fanleaf virus determines symptoms in Nicotiana species. J. Gen. Virol. 94:2803-2813.

Viry, M., Serghini, M. A., Hans, F., Ritzenthaler, C., Pinck, M., and Pinck, L. 1993. Biologically active transcripts from cloned cDNA of genomic grapevine fanleaf nepovirus RNAs. J. Gen. Virol. 74:169-174.

Yang, J., Yan, R., Roy, A., Xu, D., Poisson, J., and Zhang, Y. 2015. The I-TASSER suite: Protein structure and function prediction. Nat. Methods 12:7-8.

Zhang, C., Wu, Z., Li, Y., and Wu, J. 2015. Biogenesis, function, and applications of virus-derived small RNAs in plants. Front. Microbiol. 6: 1237.

AUTHOR-RECOMMENDED INTERNET RESOURCES

I-TASSER server: https://zhanglab.ccmb.med.umich.edu/I-TASSER Simple Modular Architecture Research Tool: smart.embl-heidelberg.de 